\title{
Preoperative Opioid Misuse is Associated With Increased Morbidity and Mortality After Elective Orthopaedic Surgery
}

\author{
Mariano E. Menendez MD, David Ring MD, PhD, \\ Brian T. Bateman MD, MSc
}

Received: 8 October 2014/Accepted: 27 January 2015/Published online: 19 February 2015

(C) The Association of Bone and Joint Surgeons (B) 2015

\begin{abstract}
Background Many patients having discretionary orthopaedic surgery take opioids daily, either with a prescription or illicitly, however little is known regarding the prevalence and effect of high-risk opioid use (eg, abuse, dependence) in the perioperative orthopaedic setting.

Questions/purposes We sought (1) to determine the prevalence of opioid abuse and dependence in patients undergoing major elective orthopaedic surgery; (2) to characterize the relationship of opioid abuse and dependence with in-hospital postoperative mortality and adverse events, failure to rescue, prolonged length of stay, and nonroutine disposition; and (3) to identify factors associated with high-risk opioid use.
\end{abstract}

\section{Each author certifies that he or she, or a member of his or her immediate family, has no funding or commercial associations (eg, consultancies, stock ownership, equity interest, patent/licensing arrangements, etc) that might pose a conflict of interest in connection with the submitted article. \\ All ICMJE Conflict of Interest Forms for authors and Clinical Orthopaedics and Related Research ${ }^{\circledR}$ editors and board members are on file with the publication and can be viewed on request. This work was performed at the Orthopaedic Hand and Upper Extremity Service, Massachusetts General Hospital, Boston, MA, USA}

Electronic supplementary material The online version of this article (doi:10.1007/s11999-015-4173-5) contains supplementary material, which is available to authorized users.

M. E. Menendez ( $\square)$, D. Ring

Orthopaedic Hand and Upper Extremity Service, Yawkey

Center, Suite 2100, Boston, MA 02114, USA

e-mail: marianofurrer@gmail.com

M. E. Menendez, D. Ring

Department of Orthopaedic Surgery, Massachusetts General

Hospital, Boston, MA, USA
Methods We used coding data collected in discharge records from the Nationwide Inpatient Sample (20022011). We analyzed changes with time in the prevalence of opioid abuse and dependence on admission. Finally, we used multivariate regression modeling to measure the association of opioid abuse and dependence with in-hospital postoperative mortality, morbidity, and resource utilization, and to identify factors associated with high-risk opioid use.

Results The prevalence of opioid abuse and dependence increased from $0.095 \%$ in 2002 to $0.24 \%$ in 2011 , an increase of $152 \%(\mathrm{p}<0.001)$. Opioid abuse and dependence were associated with increased inpatient mortality (odds ratio [OR], 3.7; 95\% CI, 2.7-5.1) and aggregate morbidity (OR, 2.31 ; 95\% CI, 2.2-2.4), including induced mental disorder (OR, 5.9; 95\% CI, 5.4-6.3), respiratory failure (OR, 3.1; 95\% CI, 2.7-3.6), surgical site infection (OR, 2.5; 95\% CI, 2.0-3.0), mechanical ventilation (OR, 2.3; 95\% CI, 2.0-2.5), pneumonia (OR, 2.1; 95\% CI, 1.8-2.3), myocardial infarction (OR, 1.9; 95\% CI, 1.3-2.6), and postoperative ileus or other gastrointestinal events (OR, 1.4; 95\% CI, 1.3-1.6) ( $\mathrm{p}<0.001$ for all listed entities). Abuse and dependence also were associated with increased risk for prolonged hospital length of stay (OR, 2.5; 95\% CI, 2.4-2.5), nonroutine discharge (OR, 2.2; 95\% CI, 2.2-2.3), and failure to rescue (OR, 2.0; 95\% CI, 1.4-2.8). High-risk opioid users were more likely to be younger, male,

\author{
B. T. Bateman \\ Department of Anesthesia, Critical Care, and Pain Medicine, \\ Massachusetts General Hospital, Boston, MA, USA \\ B. T. Bateman \\ Division of Pharmacoepidemiology and Pharmacoeconomics, \\ Department of Medicine, Brigham and Women's Hospital, \\ Harvard Medical School, Boston, MA, USA
}


nonwhite, Medicaid-insured patients with mental health and substance use disorders, and to be undergoing spine surgery. Hospital-related characteristics included urban setting, geographic location in the Northeast or West, and serving as a teaching facility.

Conclusion Opioid abuse and dependence are increasing rapidly among orthopaedic surgical inpatients and are associated with considerable postoperative morbidity and mortality and resource utilization. We recommend that orthopaedic surgeons screen patients carefully for opioid misuse preoperatively, help patients who are using opioids inappropriately to discontinue them before scheduling elective surgery, decline to perform elective surgery in patients who misuse opioids, and closely monitor patients who are habituated to opioids at the time they undergo surgery.

Level of Evidence Level III, prognostic study.

\section{Introduction}

Opioids often are prescribed for management of nonmalignant musculoskeletal pain $[3,12,14,32,54]$ and orthopaedic surgeons prescribe more opioids than surgeons in any other surgical specialty and are third after primary care physicians and internists -even though these top two groups are more numerous [52]. Prescription opioids represent the fastest growing type of drug abuse, the most common cause of unintentional overdose, and lead to more deaths annually than all illicit drugs combined [23, 29].

Despite uncertainty regarding the long-term effectiveness of opioids for treating chronic musculoskeletal pain [35, 43] and emerging evidence that preoperative opioid use is associated with greater pain, disability, and dissatisfaction after orthopaedic surgery [10, 25, 31, 32, 42, 53], opioids continue to be prescribed. Although it is well established that high-risk opioid use (abuse or dependence) may result from prolonged opioid exposure during the preoperative period [57], little is known about its prevalence and effect in the perioperative orthopaedic surgery setting. A better understanding of the burden of high-risk opioid use can alert orthopaedic providers to the importance of being more cautious with opioids and perhaps delaying elective surgery until patients can safely discontinue the use of these drugs.

Using a large healthcare utilization database, we performed this study (1) to determine the prevalence of opioid abuse and dependence as a coded diagnosis in patients undergoing elective orthopaedic surgery; and (2) to characterize the relationship of opioid abuse and dependence with inpatient mortality and adverse events, failure to rescue, prolonged length of stay (LOS), and nonroutine disposition. In addition, we wanted (3) to document which patient and hospital characteristics and which orthopaedic procedures are more likely to be associated with high-risk opioid use.

\section{Materials and Methods}

Encounter data for our retrospective cross-sectional analysis were abstracted from the Nationwide Inpatient Sample (NIS) for 2002 through 2011. The NIS currently constitutes the largest all-payer inpatient care database in the United States and is operated by the Agency for Healthcare Research and Quality (AHRQ) [8]. Each dataset year represents a $20 \%$ stratified sample of discharges from more than 1000 short-term and non-federal hospitals. Discharges are weighted based on the sampling scheme to permit inferences for a nationally representative population [45]. In addition to patient- and provider-related data, the NIS collects up to 25 (15 before 2009) diagnoses and 15 procedures (standardized International Classification of Diseases, 9th Revision, Clinical Modification [ICD-9-CM] codes), and captures selected hospitalization-related information, such as discharge destination and LOS. Our study was exempt from review by our institutional review board because the data are publicly available and deidentified.

\section{Identification of Sample and Definitions}

We considered all discharges with a primary procedure code (ICD-9-CM) for major orthopaedic surgery: primary THA (81.51), TKA (81.54), total shoulder arthroplasty $(81.80,81.88)$, and spinal fusion $(81.00-81.08)$. We excluded patients whose source of admission was nonelective (eg, trauma) and patients who were transferred to another acute-care hospital [37]. To characterize the association of opioid abuse and dependence with in-hospital mortality, morbidity, and resource use after orthopaedic surgery, we identified patients with a diagnosis of opioidtype dependence (ICD-9-CM codes 304.0x, 304.7x) or nondependent opioid abuse (ICD-9-CM code 305.5x). We excluded the code for "long-term (current) use of other medications" (V58.69) used in a previous study owing to its lack of specificity for opioid abuse and dependence [45].

Demographic variables were age, sex, race/ethnicity (white, black, Hispanic, other, unknown), and primary health insurance (Medicare, Medicaid, private, uninsured, other). On the basis of clinical plausibility and available evidence $[1,17,18,27,48,49]$, we selected several comorbidities that potentially could act as confounders in the associations between opioid abuse and dependence and 
postoperative events: AIDS and HIV infection, tobacco use, chronic anemia, alcohol abuse and dependence, depression, anxiety, and nonopioid drug abuse and dependence. The nonopioid drugs-illicit and prescription drugs used illicitly—considered were cannabis (ICD-9-CM codes 305.2x, 304.3x), hallucinogens (ICD-9-CM codes 305.3x, 304.5x), sedatives/hypnotics/anxiolytics (ICD-9CM codes 305.4x, 304.1x), cocaine (ICD-9-CM codes 305.6x, 304.2x), amphetamines (ICD-9-CM codes 305.7x, $304.4 \mathrm{x}$ ), antidepressants (ICD-9-CM code 305.8x), and other/unspecified substances (ICD-9-CM codes 305.9x, 304.6x, 304.8x, 304.9x) [33]. Patients with opioid and nonopioid drug abuse and dependence were counted as having a diagnosis of opioid abuse and dependence.

By using ICD-9-CM codes, we decided, a priori, to consider the following in-hospital adverse events owing to their incidence and effect in the perioperative orthopaedic surgery setting [6, 41]: myocardial infarction (410.xx), pneumonia (481, 482.x, 483.x, 484.x, 485, 486, 997.31, 997.39), respiratory failure $(518.51,518.53,518.81$, $518.84)$, surgical site infection $(996.67,998.59)$, pulmonary embolism (415.1, 415.11, 415.13, 415.19), deep vein thrombosis $(451.11,451.19,451.2,451.81,451.9,453.40-2$, 453.8-9), acute renal failure (584.x), postoperative ileus or other gastrointestinal events $(997.49,560.1,560.9,560.81$, 536.2, 537.3), induced mental disorder, including delirium and other confusional states (291.x, 292.x, 293.x), and mechanical ventilation $(93.90,96.70-72)$.

\section{Statistical Analysis}

Multivariate logistic regression models were used to assess the association of opioid abuse and dependence with predetermined study endpoints: inpatient mortality and adverse events, failure to rescue (death after an adverse event) [21], prolonged LOS ( $>75$ th percentile for each procedure) [15], and nonroutine discharge (discharged to a location other than home). All covariates (patient demographics, individual comorbidities, hospital characteristics, and procedure type) were defined a priori and entered into the models simultaneously without further selection. In addition to reporting multivariate-adjusted odds ratios (OR) with 95\% CIs, we present unadjusted OR and ageadjusted OR. We report age-adjusted OR because age was the most important confounder in the models.

There are some factors that are difficult to address in healthcare utilization data, including socioeconomic background, health literacy, diet, and nutritional status, which may influence our study endpoints. Therefore, we performed a sensitivity analysis restricted to patients with either opioid or nonopioid drug abuse and dependence [33]. Our assumption was that patients with opioid or other drug abuse and dependence were more likely to be similar in terms of potentially important unmeasured confounders than patients drawn from the general orthopaedic patient population. Thus, comparing patients with opioid abuse and dependence with patients with nonopioid drug disorders might facilitate identification of adverse inpatient events that are more likely to be causally related to the opioid abuse and dependence. As the total number of events for certain endpoints (mortality, respiratory failure, surgical site infection, myocardial infarction, thromboembolic events, and failure to rescue) precluded fitting a multivariable model that included all of the predetermined confounding variables, we decided to adjust only for age (our most important confounder) in these circumstances.

Additionally, we conducted a second sensitivity analysis to determine the association of opioid abuse and opioid dependence as separate groups with inpatient mortality, morbidity, and resource use. Although discerning between these two entities is clinically difficult, we sought to determine whether membership in these individual groups is uniquely associated with adverse events, as abuse is considered more a behavioral disorder, and dependence a physiologic state induced by chronic opioid intake [50,51].

As a secondary aim, we constructed a multivariate logistic regression model using the enter method to determine which factors were independently associated with opioid abuse and dependence in the perioperative orthopaedic setting.

\section{Results}

Among all hospitalizations for major elective orthopaedic surgery, the rate of opioid abuse and dependence was $0.2 \%$ $(15,901$ of 9,307,348; Table 1). The prevalence of opioid abuse and dependence in orthopaedic surgery increased by $152 \%$ during the 10 -year study period, from 0.95 per 1000 discharges in 2002 to 2.4 per 1000 discharges in 2011 ( $\mathrm{p}$ for trend, $<0.001$; Fig. 1). The prevalence of opioid abuse and dependence was particularly high among patients younger than 55 years (3.9 per 1000 discharges; Fig. 1). Spinal fusion was the orthopaedic procedure with the highest prevalence of patients who had opioid abuse and dependence, with an upward trend of abuse and dependence with time (from 1.7 per 1000 discharges in 2002 to 3.6 per 1000 discharges in 2011; Fig. 2).

After adjusting for demographics, comorbidities, procedure type, and hospital characteristics in multivariate modeling (Table 2), opioid abuse and dependence were associated with increased inpatient mortality (OR, 3.7; 95\% CI, 2.7-5.1) and aggregate morbidity (OR, 2.3; 95\% CI, 2.2-2.4), including (in decreasing order of magnitude of effect estimate): induced mental disorder (OR, 5.9; $95 \%$ 
Table 1. Characteristics of the study population

\begin{tabular}{|c|c|c|c|}
\hline Parameter & $\begin{array}{l}\text { Patients with opioid- } \\
\text { use disorder }\end{array}$ & $\begin{array}{l}\text { Patients without opioid- } \\
\text { use disorder }\end{array}$ & $\begin{array}{l}\text { Opioid-use disorder, } \\
\text { rate per } 1000\end{array}$ \\
\hline Weighted number (\%) & $15,901(0.2)$ & 9,291,447 (99.8) & 1.7 \\
\hline Age, years, mean $\pm S D$ & $52 \pm 12$ & $62 \pm 14$ & Not applicable \\
\hline \multicolumn{4}{|l|}{ Sex, \% } \\
\hline Women & 49 & 59 & 1.4 \\
\hline Men & 51 & 41 & 2.2 \\
\hline \multicolumn{4}{|l|}{ Race/ethnicity, \% } \\
\hline White & 62 & 64 & 1.7 \\
\hline Black & 8.1 & 5.3 & 2.6 \\
\hline Hispanic & 4.2 & 2.8 & 2.6 \\
\hline Other & 1.9 & 2.5 & 1.3 \\
\hline Unknown & 24 & 25 & 1.6 \\
\hline \multicolumn{4}{|l|}{ Primary health insurance, $\%$} \\
\hline Private & 43 & 43 & 1.7 \\
\hline Medicare & 31 & 48 & 1.1 \\
\hline Medicaid & 17 & 3.4 & 8.5 \\
\hline Other & 1.1 & 0.7 & 2.8 \\
\hline \multicolumn{4}{|l|}{ Comorbid conditions, $\%$} \\
\hline Alcohol abuse/dependence & 8.9 & 0.90 & 17 \\
\hline Nonopioid drug abuse/dependence & 7.6 & 0.30 & 48 \\
\hline AIDS/HIV & 0.90 & 0 & 32 \\
\hline Tobacco use & 34 & 10 & 5.7 \\
\hline Chronic anemia & 13 & 11 & 2.0 \\
\hline Depression & 28 & 11 & 4.6 \\
\hline Anxiety & 11 & 4.1 & 4.6 \\
\hline \multicolumn{4}{|l|}{ Hospital teaching status, $\%$} \\
\hline Nonteaching & 41 & 53 & 1.3 \\
\hline Teaching & 59 & 48 & 2.1 \\
\hline \multicolumn{4}{|l|}{ Hospital location, $\%$} \\
\hline Urban & 95 & 90 & 1.8 \\
\hline Rural & 5.0 & 10 & 0.90 \\
\hline \multicolumn{4}{|l|}{ Hospital geographic region, $\%$} \\
\hline Northeast & 25 & 19 & 2.2 \\
\hline Midwest & 23 & 29 & 1.3 \\
\hline South & 32 & 40 & 1.4 \\
\hline West & 21 & 12 & 3.0 \\
\hline \multicolumn{4}{|l|}{ Procedure type, $\%$} \\
\hline THA & 22 & 22 & 1.7 \\
\hline TKA & 29 & 47 & 1.0 \\
\hline Spinal fusion & 48 & 29 & 2.8 \\
\hline Total shoulder arthroplasty & 1.8 & 2.2 & 1.4 \\
\hline
\end{tabular}

CI, 5.4-6.3), respiratory failure (OR, 3.1; 95\% CI, 2.7-3.6), surgical site infection (OR, 2.5; 95\% CI, 2.0-3.0), mechanical ventilation (OR, 2.3; 95\% CI, 2.0-2.5), pneumonia (OR, 2.1; 95\% CI, 1.8-2.3), myocardial infarction (OR, 1.9; 95\% CI, 1.3-2.6), and postoperative ileus or other gastrointestinal events (OR, 1.4; 95\% CI, 1.3-1.6). Opioid abuse and dependence were also associated with greater risk for prolonged LOS (OR, 2.5; 95\% CI, 2.4-2.5), nonroutine discharge (OR, 2.2; 95\% CI, 2.2-2.3), and failure to rescue (OR, 2.0; 95\% CI, 1.4-2.8) ( $\mathrm{p}<0.001$ for all listed entities). We found no relationship between opioid abuse and dependence and the development of acute renal failure or thromboembolic events. In sensitivity analyses restricted to patients who were opioid 


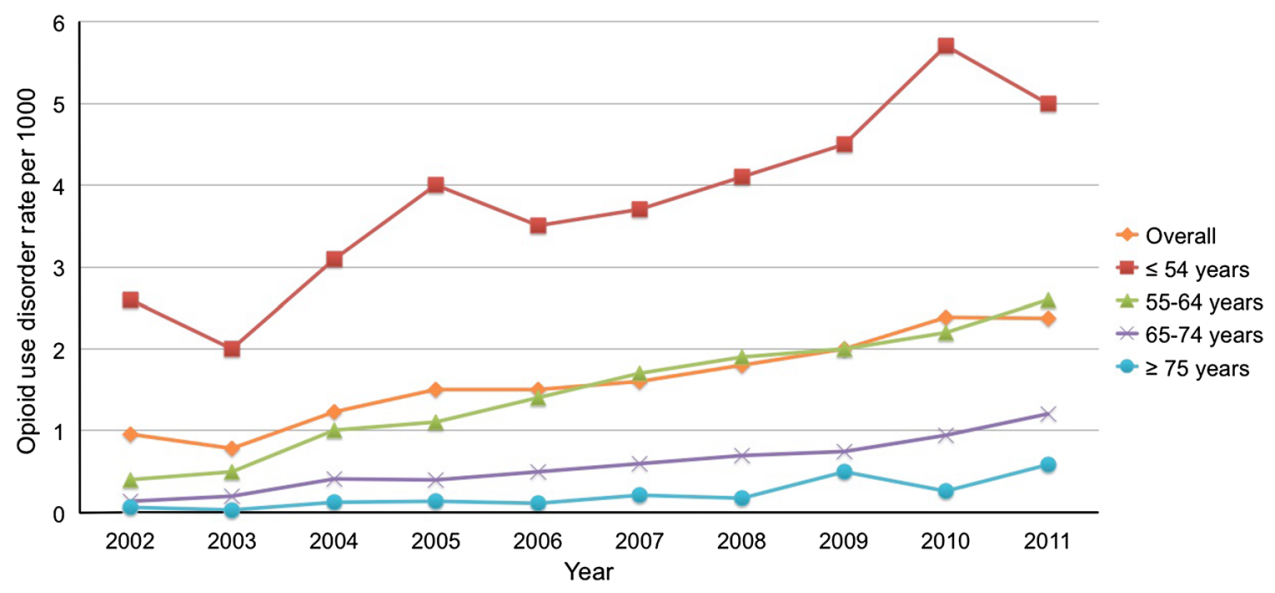

Fig. 1 The graph shows opioid abuse and dependence per 1000 orthopaedic inpatients, overall and by age, in the United States from 2001 to 2011.

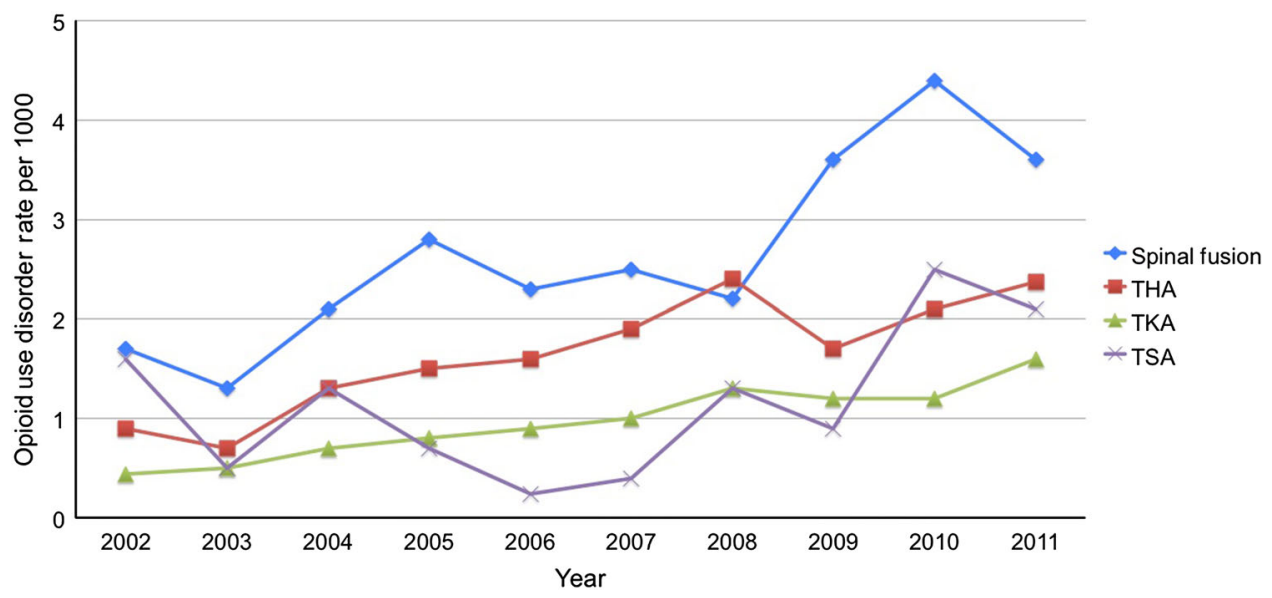

Fig. 2 The graph shows opioid abuse and dependence per 1000 orthopaedic inpatients by procedure type in the United States from 2002 to 2011. TSA $=$ total shoulder arthroplasty.

and nonopioid-dependent or opioid-abusing (Table 3), opioid abuse and dependence were independently associated with increased mortality (age-adjusted OR, 2.1; 95\% CI, 1.3-3.4), mechanical ventilation (OR, 1.8; 95\% CI, $1.5-2.1$ ), respiratory failure (age-adjusted $\mathrm{OR}, 1.8 ; 95 \% \mathrm{CI}$, 1.5-2.3), surgical site infection (age-adjusted OR, 1.6; 95\% CI, 1.2-2.2), pneumonia (OR, 1.6; 95\% CI, 1.3-1.8), postoperative ileus or other gastrointestinal events (ageadjusted OR, 1.3; 95\% CI, 1.1-1.6), failure to rescue (ageadjusted OR, 2.4; 95\% CI, 1.4-4.2), prolonged LOS (OR, $1.7 ; 95 \% \mathrm{CI}, 1.6-1.8$ ), and nonhomebound discharge (OR, $1.3 ; 95 \%$ CI, 1.3-1.4). Opioid abuse and dependence were not associated with the occurrence of myocardial infarction, thromboembolic events, and induced mental disorder, but were linked to decreased likelihood of acute renal failure (OR, 0.76; 95\% CI, 0.62-0.92). When assessing associations of inpatient events with opioid abuse and dependence as separate groups (Appendix 1. Supplemental materials are available with the online version of $\mathrm{CORR}^{\circledR}$ ), opioid dependence generally exerted more influence (higher OR) on every event, with the exceptions of surgical site infection and failure to rescue.

Patient-related factors associated with opioid abuse and dependence during the perioperative orthopaedic setting included decreasing age (OR, 0.70 per 10-year increase, 95\% CI, 0.70-0.71), male sex (OR, 1.5; 95\% CI, 1.4-1.5), black race (OR, 1.2; 95\% CI, 1.1-1.3), Hispanic (OR, 1.1; 95\% CI, 1.02-1.2), and public insurance (Medicaid: OR, 2.4; 95\% CI, 2.3-2.5; Medicare: OR, 1.4; 95\% CI, 1.3-1.4). We were unable to control for important patient-level factors (eg, socioeconomic background, homelessness, health literacy, diet, nutritional status). In decreasing order of magnitude, the comorbidities associated with opioid abuse and dependence consisted of nonopioid drug abuse and 


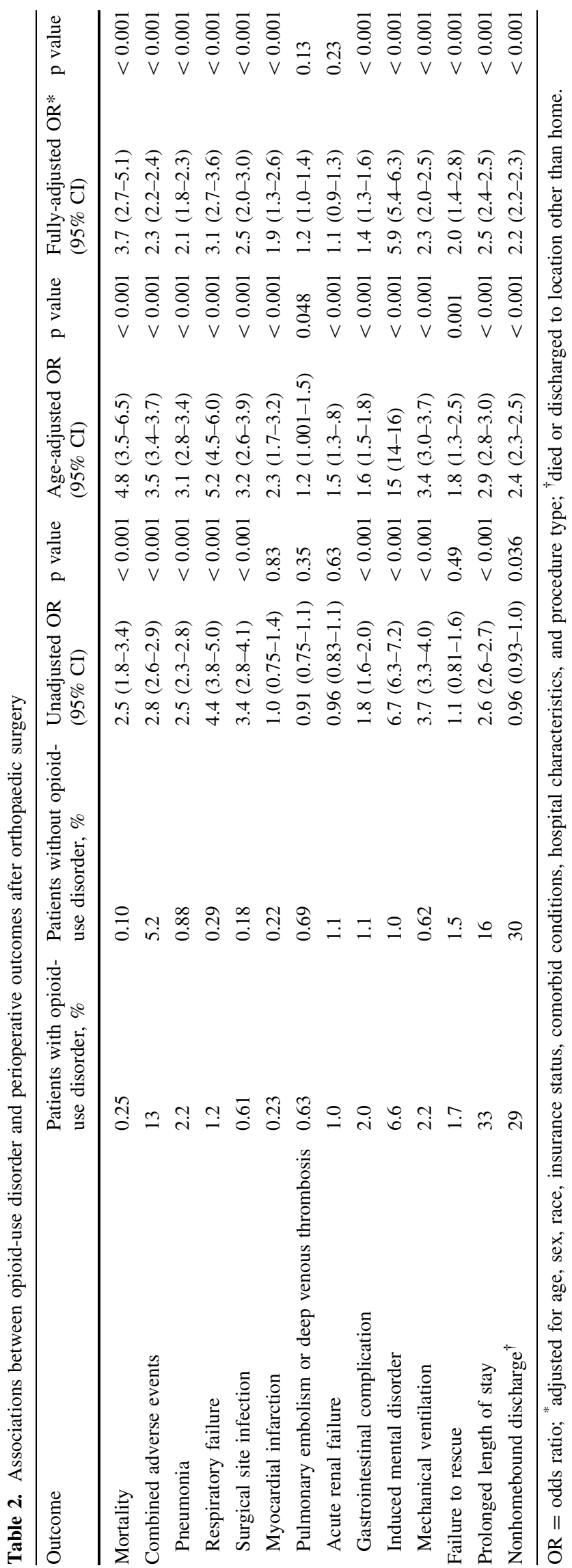

dependence (OR, 6.0; 95\% CI, 5.6-6.5), alcohol abuse and dependence (OR, 3.8; 95\% CI, 3.5-4.0), AIDS/HIV infection (OR, 5.0; 95\% CI, 4.1-5.9), depression (OR, 2.8; 95\% CI, 2.7-2.9), tobacco use (OR, 2.4; 95\% CI, 2.3-2.5), anxiety (OR, 2.1; 95\% CI, 2.0-2.3), and chronic anemia (OR, 1.5; 95\% CI, 1.5-1.6). Compared with THA, spinal fusion was the only procedure linked to opioid abuse and dependence (OR, 1.1; 95\% CI, 1.04-1.1). Hospital-related characteristics associated with opioid abuse and dependence included location in an urban area (OR, 1.6; 95\% CI, 1.5$1.8)$ and in the Northeast (OR, 1.6; 95\% CI, 1.5-1.7) or West (OR, 2.4; 95\% CI, 2.3-2.5, compared with the South), and teaching setting (OR, 1.3; 95\% CI, 1.3-1.4) (Table 4).

\section{Discussion}

Opioids often are prescribed for management of nonmalignant musculoskeletal pain $[3,12,14,32,54]$ and orthopaedic surgeons prescribe more opioids than surgeons from any other surgical specialty and are third in line after primary care physicians and internists even though these top two groups are more numerous [52]. As a result, more than 16,000 deaths per year and USD 55 billion of increased costs have been attributed to overuse of opioids [7, 29]. During the last one to two decades, there has been a dramatic increase in preoperative use of opioid medications in patients undergoing elective orthopaedic surgery $[14,56]$. Yet little is known regarding the effect of this trend on perioperative morbidity and mortality in this patient group. Our findings show that opioid abuse and dependence are increasing rapidly among orthopaedic surgical inpatients and are associated with a marked increase in the risk of postoperative mortality, morbidity, and resource use.

Our study was subject to several limitations inherent to the analysis of data originally intended for billing purposes $[20,24]$. First, as in all claims-based studies, coding misclassification can occur. It has been shown that administrative data tend to have high specificity (that is, a low false-positive rate) but low sensitivity (a high falsenegative rate) in identifying comorbidities and complications [11, 22]. Thus, if anything, our data source underestimates the prevalence of opioid abuse and dependence. Because the NIS contains no personal identifiers, validation of diagnoses and procedures through cross-referencing medical records was not possible. Since the use of different large datasets can generate disparate results $[5,8$, 9], it would be interesting to compare our findings in the NIS with those of other administrative databases (eg, the National Hospital Discharge Survey) and clinical registries (eg, the National Surgical Quality Improvement Program [NSQIP]). However, the NSQIP currently does not capture 


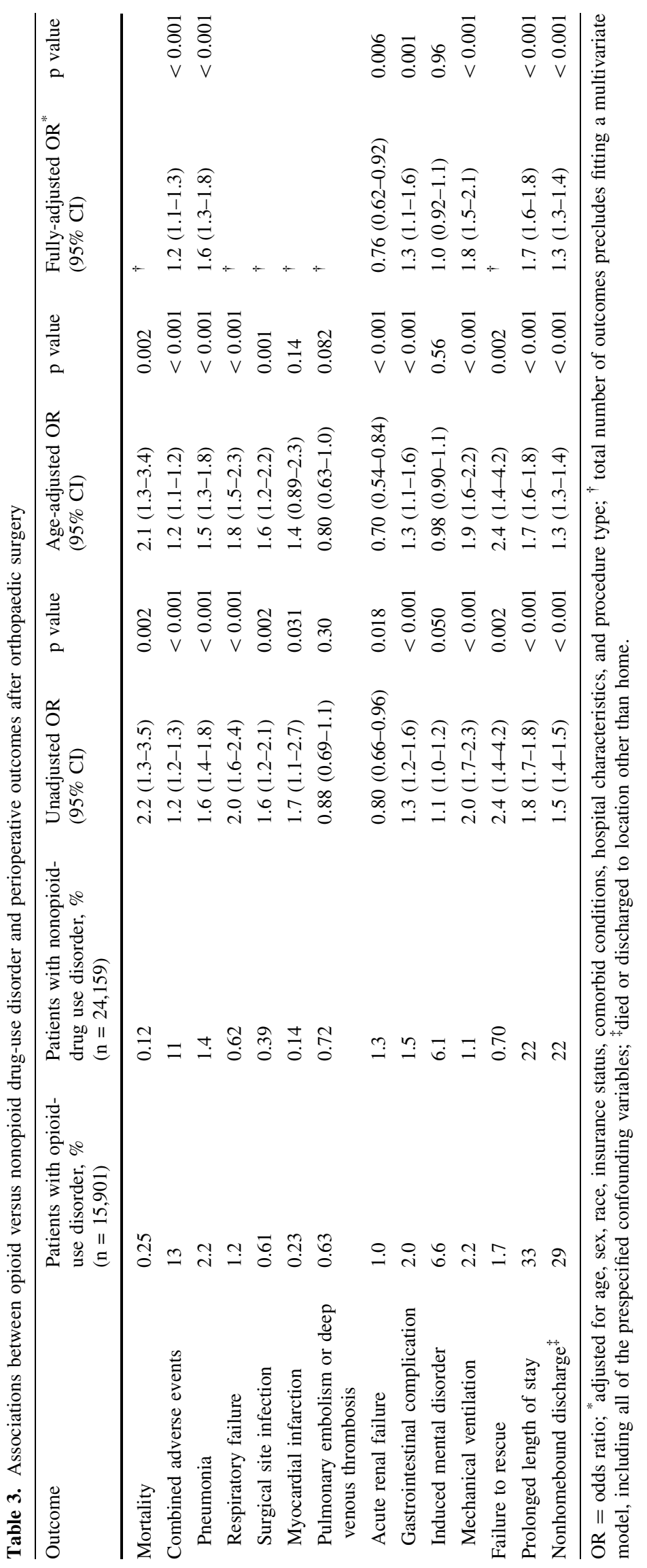


Table 4. Multivariate analysis of factors associated with opioid-use disorder in elective orthopaedic surgery

\begin{tabular}{|c|c|c|c|c|}
\hline Predictor & Coefficient $(\beta)$ & OR & $95 \% \mathrm{CI}$ & $\mathrm{p}$ value \\
\hline Age, per 10-year increase & -0.35 & 0.70 & $0.70-0.71$ & $<0.001$ \\
\hline Male sex (reference: woman) & 0.39 & 1.5 & $1.4-1.5$ & $<0.001$ \\
\hline \multicolumn{5}{|l|}{ Race (reference: white) } \\
\hline Black & 0.17 & 1.2 & $1.1-1.3$ & $<0.001$ \\
\hline Hispanic & 0.099 & 1.1 & $1.02-1.2$ & 0.017 \\
\hline Other & -0.31 & 0.73 & $0.65-0.82$ & $<0.001$ \\
\hline Unknown & -0.021 & 0.98 & $0.94-1.0$ & 0.31 \\
\hline \multicolumn{5}{|l|}{ Primary health insurance (reference: private) } \\
\hline Medicare & 0.31 & 1.4 & $1.3-1.4$ & $<0.001$ \\
\hline Medicaid & 0.88 & 2.4 & $2.3-2.5$ & $<0.001$ \\
\hline Other & 0.22 & 1.2 & $1.1-1.4$ & 0.005 \\
\hline Unknown & 0.12 & 1.1 & $1.1-1.2$ & $<0.001$ \\
\hline \multicolumn{5}{|l|}{ Comorbid conditions, $\%$} \\
\hline Alcohol abuse/dependence & 1.3 & 3.8 & $3.5-4.0$ & $<0.001$ \\
\hline Nonopioid drug abuse/dependence & 1.8 & 6.0 & $5.6-6.5$ & $<0.001$ \\
\hline AIDS/HIV & 1.6 & 5.0 & $4.1-5.9$ & $<0.001$ \\
\hline Tobacco use & 0.86 & 2.4 & $2.3-2.5$ & $<0.001$ \\
\hline Chronic anemia & 0.43 & 1.5 & $1.5-1.6$ & $<0.001$ \\
\hline Depression & 1.0 & 2.8 & $2.7-2.9$ & $<0.001$ \\
\hline Anxiety & 0.77 & 2.1 & $2.0-2.3$ & $<0.001$ \\
\hline Teaching hospital (reference: nonteaching hospital) & 0.28 & 1.3 & $1.3-1.4$ & $<0.001$ \\
\hline Urban hospital (reference: rural hospital) & 0.50 & 1.6 & $1.5-1.8$ & $<0.001$ \\
\hline \multicolumn{5}{|l|}{ Hospital geographic region (reference: South) } \\
\hline Northeast & 0.48 & 1.6 & $1.5-1.7$ & $<0.001$ \\
\hline Midwest & -0.026 & 0.97 & $0.93-1.02$ & 0.27 \\
\hline West & 0.88 & 2.4 & $2.3-2.5$ & $<0.001$ \\
\hline \multicolumn{5}{|l|}{ Procedure type (reference: THA) } \\
\hline TKA & -0.18 & 0.84 & $0.80-0.87$ & $<0.001$ \\
\hline Spinal fusion & 0.085 & 1.1 & $1.04-1.1$ & $<0.001$ \\
\hline Total shoulder arthroplasty & 0.080 & 1.1 & $0.96-1.2$ & 0.20 \\
\hline
\end{tabular}

$\mathrm{OR}=$ odds ratio.

data regarding opioid use. Another limitation was our inability to adjust for opioid exposure patterns (such as timing, duration, and amount) and classes of opioid drugs, which might influence events. It is possible that some patients with a coded opioid abuse and dependence diagnosis had low-level use of opioids. However, if this had been the case, the prevalence of opioid abuse and dependence in our study would have been much higher than $0.2 \%$. For instance, in a recent study of patients undergoing spine surgery, $56 \%$ reported some degree of preoperative opioid use [32]. Third, the availability of 10 more diagnosis codes in the NIS starting in 2009 might explain some of the noted increase in opioid abuse and dependence although this seems unlikely, given that very few patients have more than 15 diagnoses. Fourth, as it often is difficult to distinguish between opioid abuse and dependence in the hospital setting, we decided to combine the two entities for the primary analysis-an approach that is consistent with the definition of "opioid use disorder" in the 5th edition of the Diagnostic and Statistical Manual of Mental Disorders (DSM-5) [2, 4]. In our sensitivity analysis restricted to patients who abused opioids and those who were dependent on opioids, most associations with mortality, morbidity, and resource use remained significant in both cohorts. Fifth, we were unable to document postdischarge events, which limited the interpretation of the effect of opioid abuse and dependence on patients having orthopaedic surgery. Sixth, multiple comparisons in our analysis increase the possibility of false-positive associations (type I error), and the presented findings should be confirmed in other populations and data settings. Finally, results in large-scale studies can be statistically significant yet clinically insignificant. The reader, therefore, should consider whether findings with relatively small effects sizes 
are clinically relevant and not influenced by unmeasured confounders (eg, association of nonwhite race/ethnicity with opioid misuse). The effect size for many of the associations that we reported are large $(>2)$, and thus are likely to be clinically important.

In our sample, approximately one in $500(0.2 \%)$ patients undergoing major elective orthopaedic surgery was coded as abusing or dependent on opioids. We identified a considerable increase $(152 \%)$ in the prevalence of coding for opioid abuse and dependence among orthopaedic inpatients with time. To our knowledge, this is one of the first studies to report the incremental prevalence of opioid misuse in the perioperative orthopaedic surgery setting. It is possible that, to some extent, the observed increase in opioid abuse and dependence might be related to growing awareness of these disorders by coders who might be more likely to prioritize and include ICD-9-CM diagnosis codes for opioid misuse. Maeda et al. [33] recently reported that the prevalence of opioid abuse and dependence in women hospitalized for delivery across the United States increased by $127 \%$, from 1.7 per 1000 delivery admissions in 1998 to 3.9 per 1000 delivery admissions in 2011. Although the observed frequency of opioid abuse and dependence among orthopaedic surgical inpatients could be considered small, the clinical and economic burdens to healthcare systems are substantial [30, 36, 40, 44].

Patients with opioid abuse and dependence undergoing orthopaedic surgery had increased odds of early postoperative morbidity and mortality and also were more likely to experience a prolonged and complicated recovery, as reflected by the longer hospital LOS and increased nonroutine discharge. It is well established that patients with opioid-use disorders have a tolerance develop to the analgesic effects of opioids and require higher doses to obtain adequate pain relief postoperatively [19], yet they are just as vulnerable as the general population to the sedative effects of opioids, which may explain the increased odds of respiratory compromise, mechanical ventilation, and mortality in our analysis. The recognized difficulty in achieving adequate pain control among patients with opioid abuse and dependence was likely one of the main reasons for longer LOS; this finding was consistent with a recent study among women hospitalized for delivery in the United States [33]. Although functional outcomes were not assessed in our study, the greater need for posthospitalization care could further be interpreted as a less rapid return of independent functional mobility in this patient population $[38,39]$. It is possible that lower levels of selfefficacy for managing pain - greater pain catastrophizingand resilience in maintaining function among chronic opioid users contributed to the higher rate of posthospitalization care observed in our study [26, 47], and also may partly explain why these patients tend to have worse functional outcomes after orthopaedic procedures [31, 32 , 42, 57].

Opioid prescriptions have increased dramatically during the last two decades, largely driven by concerns in the late 1990s about the undertreatment of pain. This has been accompanied by relaxation of laws regarding governing prescribing opioids for treatment of chronic noncancer pain, marketing by the pharmaceutical industry, and promotion of opioids by numerous physicians. We found that high-risk opioid users were more likely to be younger, male, nonwhite, Medicaid-insured patients, with mental health and substance-use disorders, undergoing spine surgery. However, the ORs suggesting more opioid misuse in black and Hispanic patients were small and likely could be explained by factors not accounted for in our analysis (eg, differences in coding practices between different types of hospitals, poverty, homelessness, health literacy). In agreement with data from the primary care and interventional pain management settings [28, 34], high-risk use of opioids was more common in younger patients. Our finding that male sex was associated with opioid abuse and dependence is consistent with prior research using claims data to identify patients at risk for inappropriate opioid use $[46,55]$. The observation that patients having spinal fusion showed the highest prevalence of opioid abuse and dependence was not surprising given that opioids play an increasingly pivotal role in the long-term management of chronic back pain, which is the primary reason for patients to undergo such procedures [13, 14]. Patients with mental health and nonopioid substance use disorders had greater odds of abusing or being dependent on opioids, thus confirming the generalizability of previous studies to orthopaedic surgical inpatients [16, 17, 46, 49, 55]. Quality and safety initiatives aimed at reducing opioid misuse in the orthopaedic setting should primarily target this at-risk population, and be particularly implemented at urban teaching hospitals in the Northeast and West that function as "safety net" providers. The geographic variation in opioid misuse should be examined more closely to determine whether policies and laws, enforcement level, physician-prescribing practices, or other factors contribute to these differences.

Despite the limitations associated with data analysis from healthcare utilization databases, our study provided evidence that high-risk opioid use is increasing among patients undergoing elective orthopaedic surgery and was associated with a greater likelihood of in-hospital postoperative morbidity and mortality and healthcare resource utilization. These findings call for further development of multidisciplinary approaches to effectively reduce opioid prescribing and associated adverse consequences in the orthopaedic surgery setting. We recommend that orthopaedic surgeons screen patients carefully for opioid misuse 
preoperatively, help patients who are using opioids inappropriately to discontinue them before scheduling elective surgery, decline to perform elective surgery in patients who misuse opioids, and closely monitor patients who are habituated to opioids at the time they undergo surgery.

\section{References}

1. Altice FL, Bruce RD, Lucas GM, Lum PJ, Korthuis PT, Flanigan TP, Cunningham CO, Sullivan LE, Vergara-Rodriguez P, Fiellin DA, Cajina A, Botsko M, Nandi V, Gourevitch MN, Finkelstein R; BHIVES Collaborative. HIV treatment outcomes among HIV-infected, opioid-dependent patients receiving buprenorphine/naloxone treatment within HIV clinical care settings: results from a multisite study. J Acquir Immune Defic Syndr. 2011;56(suppl 1):S22-32.

2. American Psychiatric Association. Diagnostic and Statistical Manual of Mental Disorders-Dsm-5. 5th ed. Washington, DC: American Psychiatric Association; 2013.

3. Armaghani SJ, Lee DS, Bible JE, Archer KR, Shau DN, Kay H, Zhang C, McGirt MJ, Devin CJ. Preoperative narcotic use and its relation to depression and anxiety in patients undergoing spine surgery. Spine (Phila Pa 1976). 2013;38:2196-2000.

4. Ballantyne JC, Sullivan MD, Kolodny A. Opioid dependence vs addiction: a distinction without a difference? Arch Intern Med. 2012;172:1342-1343.

5. Bekkers S, Bot AG, Makarawung D, Neuhaus V, Ring D. The National Hospital Discharge Survey and Nationwide Inpatient Sample: the databases used affect results in THA research. Clin Orthop Relat Res. 2014;472:3441-3449.

6. Bhattacharyya T, Iorio R, Healy WL. Rate of and risk factors for acute inpatient mortality after orthopaedic surgery. $J$ Bone Joint Surg Am. 2002;84:562-572.

7. Birnbaum HG, White AG, Schiller M, Waldman T, Cleveland JM, Roland CL. Societal costs of prescription opioid abuse, dependence, and misuse in the United States. Pain Med. 2011; 12:657-667.

8. Bohl DD, Basques BA, Golinvaux NS, Baumgaertner MR, Grauer JN. Nationwide Inpatient Sample and National Surgical Quality Improvement Program give different results in hip fracture studies. Clin Orthop Relat Res. 2014;472:1672-1680.

9. Bohl DD, Russo GS, Basques BA, Golinvaux NS, Fu MC, Long WD 3rd, Grauer JN. Variations in data collection methods between national databases affect study results: a comparison of the nationwide inpatient sample and national surgical quality improvement program databases for lumbar spine fusion procedures. J Bone Joint Surg Am. 2014;96:e193.

10. Bot AG, Bekkers S, Arnstein PM, Smith RM, Ring D. Opioid use after fracture surgery correlates with pain intensity and satisfaction with pain relief. Clin Orthop Relat Res. 2014;472:2542-2549.

11. Bozic KJ, Bashyal RK, Anthony SG, Chiu V, Shulman B, Rubash HE. Is administratively coded comorbidity and complication data in total joint arthroplasty valid? Clin Orthop Relat Res. 2013;471: 201-205.

12. Caudill-Slosberg MA, Schwartz LM, Woloshin S. Office visits and analgesic prescriptions for musculoskeletal pain in US: 1980 vs. 2000. Pain. 2004;109:514-519.

13. Chaparro LE, Furlan AD, Deshpande A, Mailis-Gagnon A, Atlas S, Turk DC. Opioids compared to placebo or other treatments for chronic low-back pain. Cochrane Database Syst Rev. 2013;8: CD004959.
14. Deyo RA, Mirza SK, Turner JA, Martin BI. Overtreating chronic back pain: time to back off? J Am Board Fam Med. 2009;22:6268.

15. Dimick JB, Cowan JA Jr, Colletti LM, Upchurch GR Jr. Hospital teaching status and outcomes of complex surgical procedures in the United States. Arch Surg. 2004;139:137-141.

16. Edlund MJ, Martin BC, Fan MY, Devries A, Braden JB, Sullivan MD. Risks for opioid abuse and dependence among recipients of chronic opioid therapy: results from the TROUP study. Drug Alcohol Depend. 2010;112:90-98.

17. Edlund MJ, Steffick D, Hudson T, Harris KM, Sullivan M. Risk factors for clinically recognized opioid abuse and dependence among veterans using opioids for chronic non-cancer pain. Pain. 2007; 129:355-362.

18. Edlund MJ, Sullivan M, Steffick D, Harris KM, Wells KB. Do users of regularly prescribed opioids have higher rates of substance use problems than nonusers? Pain Med. 2007;8:647-656.

19. Farrell C, McConaghy P. Perioperative management of patients taking treatment for chronic pain. BMJ. 2012;345:e4148.

20. Fleischut PM, Mazumdar M, Memtsoudis SG. Perioperative database research: possibilities and pitfalls. $\mathrm{Br} J$ Anaesth. 2013;111:532-534.

21. Ghaferi AA, Birkmeyer JD, Dimick JB. Complications, failure to rescue, and mortality with major inpatient surgery in medicare patients. Ann Surg. 2009;250:1029-1034.

22. Golinvaux NS, Bohl DD, Basques BA, Grauer JN. Administrative database concerns: accuracy of International Classification of Diseases, Ninth Revision coding is poor for preoperative anemia in spinal fusion patients. Spine (Phila Pa 1976). 2014;39:20192023.

23. Grattan A, Sullivan MD, Saunders KW, Campbell CI, Von Korff MR. Depression and prescription opioid misuse among chronic opioid therapy recipients with no history of substance abuse. Ann Fam Med. 2012;10:304-311.

24. Haut ER, Pronovost PJ, Schneider EB. Limitations of administrative databases. JAMA. 2012;307:2589; author reply 25892590.

25. Helmerhorst GT, Lindenhovius AL, Vrahas M, Ring D, Kloen P. Satisfaction with pain relief after operative treatment of an ankle fracture. Injury. 2012;43:1958-1961.

26. Helmerhorst GT, Vranceanu AM, Vrahas M, Smith M, Ring D. Risk factors for continued opioid use one to two months after surgery for musculoskeletal trauma. J Bone Joint Surg Am. 2014;96:495-499.

27. Hooten WM, Shi Y, Gazelka HM, Warner DO. The effects of depression and smoking on pain severity and opioid use in patients with chronic pain. Pain. 2011;152:223-229.

28. Ives TJ, Chelminski PR, Hammett-Stabler CA, Malone RM, Perhac JS, Potisek NM, Shilliday BB, DeWalt DA, Pignone MP. Predictors of opioid misuse in patients with chronic pain: a prospective cohort study. BMC Health Serv Res. 2006;6:46.

29. Jones CM, Mack KA, Paulozzi LJ. Pharmaceutical overdose deaths, United States, 2010. JAMA. 2013;309:657-659.

30. Kane-Gill SL, Rubin EC, Smithburger PL, Buckley MS, Dasta JF. The cost of opioid-related adverse drug events. J Pain Palliat Care Pharmacother. 2014;28:282-293.

31. Lawrence JT, London N, Bohlman HH, Chin KR. Preoperative narcotic use as a predictor of clinical outcome: results following anterior cervical arthrodesis. Spine (Phila Pa 1976). 2008;33:2074-2078.

32. Lee D, Armaghani S, Archer KR, Bible J, Shau D, Kay H, Zhang C, McGirt MJ, Devin C. Preoperative opioid use as a predictor of adverse postoperative self-reported outcomes in patients undergoing spine surgery. J Bone Joint Surg Am. 2014;96:e89. 
33. Maeda A, Bateman BT, Clancy CR, Creanga AA, Leffert LR. Opioid abuse and dependence during pregnancy: temporal trends and obstetrical outcomes. Anesthesiology. 2014;121:1158-1165.

34. Manchikanti L, Cash KA, Damron KS, Manchukonda R, Pampati $\mathrm{V}$, McManus CD. Controlled substance abuse and illicit drug use in chronic pain patients: an evaluation of multiple variables. Pain Physician. 2006;9:215-225.

35. Martell BA, O'Connor PG, Kerns RD, Becker WC, Morales KH, Kosten TR, Fiellin DA. Systematic review: opioid treatment for chronic back pain: prevalence, efficacy, and association with addiction. Ann Intern Med. 2007;146:116-127.

36. McAdam-Marx C, Roland CL, Cleveland J, Oderda GM. Costs of opioid abuse and misuse determined from a Medicaid database. J Pain Palliat Care Pharmacother. 2010;24:5-18.

37. Menendez ME, Memtsoudis SG, Opperer M, Boettner F, Gonzalez Della Valle A. A nationwide analysis of risk factors for inhospital myocardial infarction after total joint arthroplasty. Int Orthop. 2014 Aug 30. [Epub ahead of print]

38. Menendez ME, Neuhaus V, Bot AG, Ring D, Johnson AH. The impact of metabolic syndrome on inpatient outcomes after isolated ankle fractures. Foot Ankle Int. 2014;35:463-470.

39. Menendez ME, Ring D. Does the timing of surgery for proximal humeral fracture affect inpatient outcomes? J Shoulder Elbow Surg. 2014;23:1257-1262.

40. Menendez ME, van Dijk CN, Ring D. Who Leaves the Hospital Against Medical Advice in the Orthopaedic Setting? Clin Orthop Relat Res. 2014 Sep 4. [Epub ahead of print]

41. Molina CS, Thakore RV, Blumer A, Obremskey WT, Sethi MK. Use of the National Surgical Quality Improvement Program in orthopaedic surgery. Clin Orthop Relat Res. 2014 Apr 5. [Epub ahead of print]

42. Morris BJ, Laughlin MS, Elkousy HA, Gartsman GM, Edwards TB. Preoperative opioid use and outcomes after reverse shoulder arthroplasty. J Shoulder Elbow Surg. 2015;24:11-16.

43. Noble M, Treadwell JR, Tregear SJ, Coates VH, Wiffen PJ, Akafomo C, Schoelles KM. Long-term opioid management for chronic noncancer pain. Cochrane Database Syst Rev. 2010:CD 006605.

44. Oderda GM, Said Q, Evans RS, Stoddard GJ, Lloyd J, Jackson K, Rublee D, Samore MH. Opioid-related adverse drug events in surgical hospitalizations: impact on costs and length of stay. Ann Pharmacother. 2007;41:400-406.
45. Patrick SW, Schumacher RE, Benneyworth BD, Krans EE, McAllister JM, Davis MM. Neonatal abstinence syndrome and associated health care expenditures: United States, 2000-2009. JAMA. 2012;307:1934-1940.

46. Rice JB, White AG, Birnbaum HG, Schiller M, Brown DA, Roland CL. A model to identify patients at risk for prescription opioid abuse, dependence, and misuse. Pain Med. 2012;13:11621173.

47. Ring D, Kadzielski J, Malhotra L, Lee SG, Jupiter JB. Psychological factors associated with idiopathic arm pain. J Bone Joint Surg Am. 2005;87:374-380.

48. Sullivan MD, Edlund MJ, Steffick D, Unutzer J. Regular use of prescribed opioids: association with common psychiatric disorders. Pain. 2005; 119:95-103.

49. Sullivan MD, Edlund MJ, Zhang L, Unutzer J, Wells KB. Association between mental health disorders, problem drug use, and regular prescription opioid use. Arch Intern Med. 2006;166: 2087-2093.

50. Volkow ND. What do we know about drug addiction? Am J Psychiatry. 2005;162:1401-1402.

51. Volkow ND, Li TK. Drugs and alcohol: treating and preventing abuse, addiction and their medical consequences. Pharmacol Ther. 2005;108:3-17.

52. Volkow ND, McLellan TA, Cotto JH, Karithanom M, Weiss SR. Characteristics of opioid prescriptions in 2009. JAMA. 2011;305: 1299-1301.

53. Vranceanu AM, Bachoura A, Weening A, Vrahas M, Smith RM, Ring D. Psychological factors predict disability and pain intensity after skeletal trauma. J Bone Joint Surg Am. 2014;96:e20.

54. Webster BS, Verma SK, Gatchel RJ. Relationship between early opioid prescribing for acute occupational low back pain and disability duration, medical costs, subsequent surgery and late opioid use. Spine (Phila Pa 1976). 2007;32:2127-2132.

55. White AG, Birnbaum HG, Schiller M, Tang J, Katz NP. Analytic models to identify patients at risk for prescription opioid abuse. Am J Manag Care. 2009;15:897-906.

56. Wright EA, Katz JN, Abrams S, Solomon DH, Losina E. Trends in prescription of opioids from 2003-2009 in persons with knee osteoarthritis. Arthritis Care Res (Hoboken). 2014;66:1489-1495.

57. Zywiel MG, Stroh DA, Lee SY, Bonutti PM, Mont MA. Chronic opioid use prior to total knee arthroplasty. J Bone Joint Surg Am. 2011;93:1988-1993. 